\title{
"Da realidade ao sonho": uma tentativa de planejamento participativo do parcelamento do solo para a Ecoagrovila Renascer desenvolvido pelo EMAU/CASAS/FAU/UnB
}

\author{
ANDRADE, Liza Maria Souza de ${ }^{1}$ \\ LOUREIRO, Vânia Raquel Teles ${ }^{2}$ \\ SILVA, Caio Frederico ${ }^{3}$ \\ MACHADO, Luiz Felipe ${ }^{4}$ \\ ${ }^{1}$ CASAS/FAU/UnB, Brasília, Brasil. lizamsa@gmail.com \\ 2PPG-FAU/UnB, Brasília, Brasil. vania.teles.loureiro@gmail.com \\ 3CASAS/FAU/UnB, Brasília, Brasil. caiosilva@unb.br \\ ${ }^{4}$ CASAS/FAU/UnB, Brasília, Brasil. luizfellipe.machado@gmail.com
}

\begin{abstract}
Resumo
Este trabalho trata do planejamento do parcelamento do solo de forma participativa para a Ecoagrovila Renascer, desenvolvido pelo escritório modelo CASAS no âmbito da disciplina de PEMAU ${ }^{1}$. A demanda surgiu por inciativa do Movimento Rio São Bartolomeu Vivo que trabalha com comunidades na bacia hidrográfica visando a regeneração das margens dos córregos da região, bem como da necessidade de buscar apoio no processo de planejamento junto ao INCRA (portaria no 321/1997) nos moldes do Projeto de Assentamento Casulo. A tipologia de assentamento trata de garantir um espaço de desenvolvimento compartilhado e descentralizado onde serão exploradas atividades agroecológicas economicamente viáveis e ecologicamente sustentáveis, com atividades agropecuárias e desenvolvimento de comunidades mais justas e conscientes. $O$ objetivo deste artigo é demonstrar o processo de planejamento baseado no conceito de Ecovila e princípios de sustentabilidade para o desenho do lugar com introdução de metodologias participativas, que envolveu estudantes e assentados do Movimento de Apoio à Trabalhadora e ao Trabalhador MATR. Foram desenvolvidas quatro propostas para 40 e 50 famílias, de 2 a 2,5 hectares por lote, em quatro níveis de realidade distintos - da realidade concreta do assentamento ao sonho comunitário dos moradores.
\end{abstract}

Palavras-Chave: Ecoagrovila Renascer, Projeto Participativo, Desenho de Ecovilas.

1 Prática em Escritório Modelo de Arquitetura e Urbanismo

\begin{abstract}
This work aims to present the participatory planning process of land division in the "Ecoagrovila Renascer". It was developed at $\mathrm{PEMAU}^{2}$, a course part of CASAS - the architecture student's office for social projects in $\mathrm{FAU} / \mathrm{UnB}$. The project demand came from "Rio São Bartolomeu Vivo Movement" which works with communities settled at the watershed of São Bartolomeu river helping them with the regeneration of local streams and supporting the legalizing processes of the settlements, legally framed by "Projeto de assentamento Casulo" from INCRA (no321/1997). Casulo is a Settlement Typology that looks after social and environmental awareness by promoting decentralized space for community development in rural areas, throughout economic and ecologically sustainable agroecological activities. This paper objective is to present a planning process based on Ecovilla's concept and Sustainability Principles for space, as well as to share the participatory methodology used that involved students and settlers from MATR a movement for workers support. As a result, 4 proposals were presented, varying from 50 to 40 families at land plots of 2 to 2,5 ha and responding to four different reality levels, allowing students to explore the way from basic reality situations to the settlers' community dreams.
\end{abstract}

Key-Words: Ecoagrovila, Participatory Project, Ecovillage.

\footnotetext{
2 Pratices of Architecture and Urbanism Model Office
} 


\section{Introdução}

O grande desafio da sustentabilidade no nível planetário passa pela produção do habitat humano que promova o equilíbrio entre a relação cidade-campo. Na visão de Peixoto e Pereira (s.d), os elementos que diferenciam o rural do urbano são: o trabalho agrícola, a relação direta com a natureza, a dispersão espacial, a menor estratificação social, decorrente da menor divisão do trabalho, o isolamento cultural e a concretude das relações interpessoais. $\mathrm{O}$ agricultor familiar desempenha inúmeras atividades, portanto, a divisão do trabalho e a diversificação de atividades são vistas como processo de desruralização.

A organização espacial associada à infraestrutura nos assentamentos rurais no Brasil sempre foi um fator que identifica a separação do campo e da cidade. Porém, atualmente abre-se para uma nova compreensão uma convergência espacial entre os polos urbano e rural com integração de territórios, sem um anular o outro, mas se influenciando mutuamente, uma nova visão do rural contemporâneo.

No que tange o planejamento do solo, a sustentabilidade territorial ou espacial, segundo Sachs (2002) está relacionada a configurações urbanas e rurais balanceadas para evitar a concentração populacional excessiva nas áreas metropolitanas. Na sua visão é necessário urbanizar o campo e ruralizar as cidades, tendo em vista a melhoria do ambiente urbano, a superação das disparidades inter-regionais e as estratégias de desenvolvimento ambientalmente seguras para áreas ecologicamente frágeis.

O urbanismo agrário é um novo conceito que envolve produção de alimentos não apenas como um meio de sobrevivência ou geração de renda, mas como uma base para promoção da vida e para estruturar os lugares em que vivemos, envolvendo o campo e a cidade. Refere-se à iniciativa de planejamento com o objetivo de promover um tipo de comunidade sustentável, que intensifica a atividade agrícola em todo o gradiente natural do campo à cidade, com níveis de ocupações diferentes, denominado "transecto", proporcionando benefícios econômicos, ambientais e sociais associados.

A determinação do zoneamento precisa consolidar espaço intraurbano, periurbano e rural em um único ecossistema urbano. A integração destes espaços complementa o rural com o autoabastecimento, fluxos comerciais e abastecimento de mercado. Portanto, os princípios derivados da permacultura, os quais induzem a consolidação de benefícios ecológicos, por meio da manutenção e implantação de cultivos na cidade e no campo, usando fundamentos da diversidade e estabilidade do ambiente natural, tornam-se fundamentais para promover a resiliência da região.

A permacultura, segundo Mollison (1998), consiste em um modelo de desenho que se conduz em estratégias e arranjos naturais do local, com o entorno, tendo por prioridade a concepção de espaços com multiplicidade funcional. $O$ desenho das Ecovilas é baseado nos princípios da permacultura e tem como prioridade: produção local de alimentos, construções ecológicas, sistemas de energias renováveis, economia solidária, processos participativos de tomada de decisões, diversidade cultural e espiritual, visão sistêmica para cuidar da saúde e da educação. Nas áreas rurais, torna-se mais simples a aplicação desses princípios, uma vez que se pode planejar e criar condições adequadas para seu desenvolvimento ao longo do tempo.

Portanto, este modelo de assentamentos humanos sustentáveis, como as Ecovilas, reconhecidos pela ONU, tornam-se bons exemplos para promover uma melhor integração da relação cidade-campo. A proposta do Programa Casulo de Assentamento, uma modalidade de Projeto de Reforma Agrária criada pela portaria do Instituto Nacional de Colonização e Reforma Agrária INCRA no 321/1997, tem como intenção minimizar a ocorrência do êxodo rural, fixando as famílias que moram nas periferias das cidades ou áreas rurais próximas aos centros urbanos em assentamentos organizados e produtivos. Segundo o INCRA, este programa 
procura garantir um espaço de desenvolvimento compartilhado e descentralizado onde serão exploradas atividades agroecológicas economicamente viáveis e ecologicamente sustentáveis, que permitam não só o bom desenvolvimento da exploração agropecuária como o desenvolvimento de uma comunidade mais justa e consciente. Os imóveis destinados a implantar um assentamento casulo devem ter capacidade de abrigar acima de 15 (quinze) famílias, com lotes individuais rurais que obedeçam a fração mínima de parcelamento de 2 ha até 4 (quatro) módulos fiscais ${ }^{3}$ referentes ao município de localização.

Situado a cerca de $24 \mathrm{~km}$ de Brasília, localizado numa área entre Sobradinho e Planaltina, no território do Distrito Federal, o assentamento Ecoagrovila Renascer, oriundo do Movimento de Apoio a Trabalhadora e ao Trabalhador Rural - MATR, se enquadra no Programa Casulo. Este Movimento foi constituído em 1999 com a mobilização de famílias vindas de cidades, em sua grande maioria de Sobradinho, Paranoá e Planaltina, sendo imigrantes de várias regiões do país, que viviam no meio rural em suas cidades de origem e se instalaram nas terras hoje reivindicadas.

Essas famílias se instalaram em 2004 às margens da Rodovia DF330, e posteriormente, com a luta pelo território, em 2007, ocuparam a Fazenda Sálvia, terra da União, que faz parte da Área de Proteção Ambiental - APA do Rio São Bartolomeu. Esta última, criada em 1983, é a maior do Distrito Federal e desempenha um importante papel de corredor de ligação entre a Estação Ecológica de Águas Emendadas, APA de Cafuringa, APA do Lago Paranoá e APA das bacias do Gama e Cabeça-de-Veado, reunindo todos os tipos de vegetação, desde o Cerradão até os Campos Rupestres. Contém representantes de diversas espécies da fauna nativa, portanto, segundo os órgãos ambientais, trata-se de uma área de relevante interesse ambiental para preservação dos córregos da

3 Por Módulo Fiscal entende-se o parâmetro de classificação dos imóveis rurais quanto ao tamanho, em hectares (Lei no 8.629, de 25 de fevereiro de 1993). região. Os mapas das figuras 1, 2 e 3 ilustram a localização do assentamento no contexto da bacia.

Figura 1: Mapa das Bacias Hidrográficas do DF.

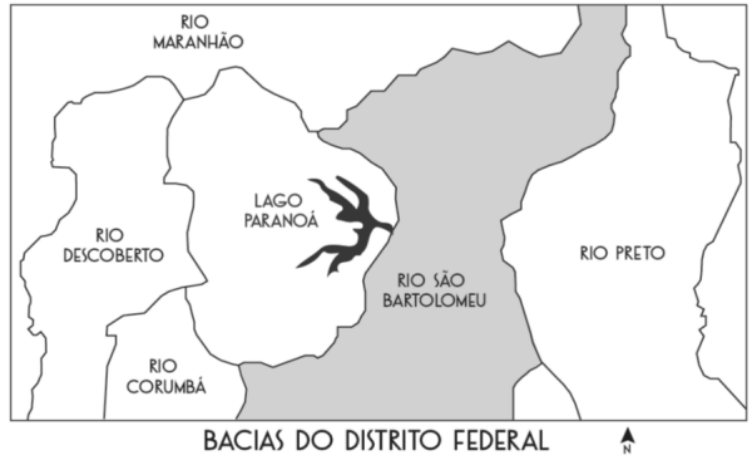

Figura 2: Mapa da localização do assentamento.

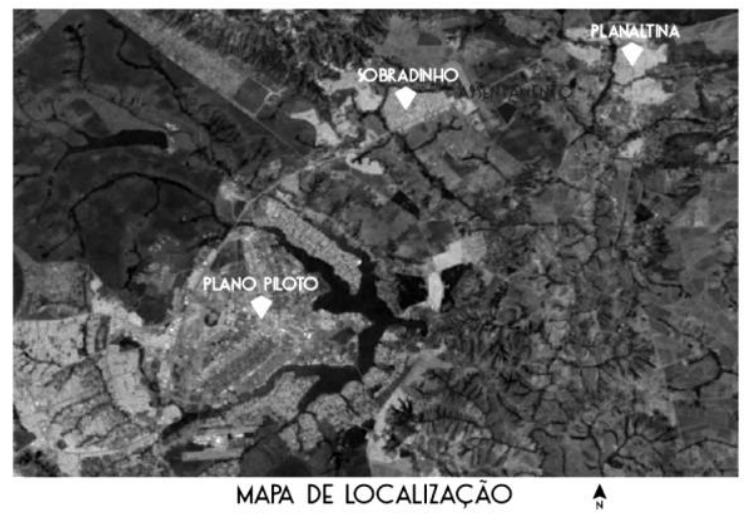

Fonte: Google Earth

Figura 3: Mapa de situação da comunidade Renascer.

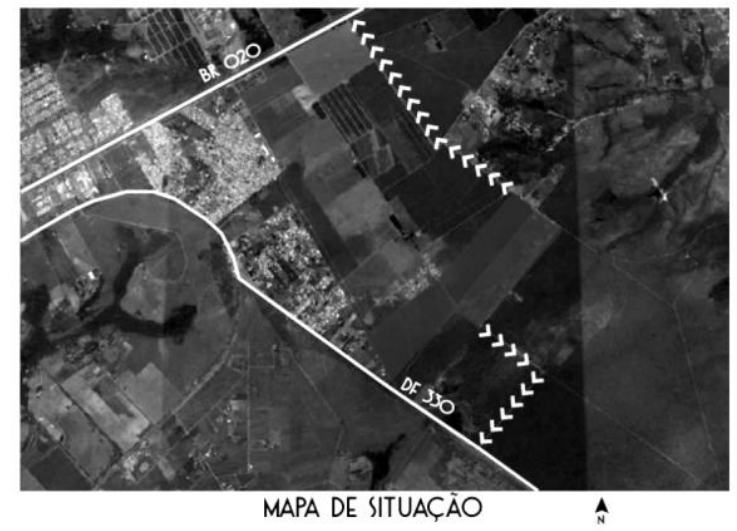

Fonte: Google Earth

Em 2008, as famílias são transferidas e montam barracos nas margens da Rodovia DF330, ficando por nove meses acampadas no local. A partir de reivindicações constantes e ações coletivas, em 2009, a União passou a área de aproximadamente 764,021 hectares para 0 
INCRA, que por sua vez, autorizou a entrada das famílias na forma de acampamentos, oriundas dos três movimentos sociais envolvidos, o MATR, o Movimento dos Trabalhadores Rurais Sem Terra - MST, e o Movimento dos Trabalhadores Desempregados - MTD.

Porém, apenas em 2010, as famílias acampadas na área tiveram conhecimento que uma Lei de Preservação de Animal Silvestre estaria impedindo o assentamento definitivo na área autorizada. Com isso, o MST decide deixar a área procurando outras alternativas na região.

Segundo o Relatório de Viabilidade Ambiental do Imóvel - RVA da Fazenda Sálvia desenvolvido pelo INCRA (BRASIL, 2013), devido às restrições impostas pela Legislação Ambiental Distrital ${ }^{4}$ da área doada ao INCRA pela Gerência Regional do Patrimônio da União - GRPU de 764,021 ha, $77,15 \%$ da área (587,0205ha) fica excluída de qualquer tipo de uso, cabendo apenas preservação e conservação, por se localizar na área de Zona de Vida Silvestre - ZVS, restando apenas $22,85 \%$ uma área de 173,66 ha, que se encontra localizada dentro dos limites da Zona de Uso Agropecuário - ZUA, que poderá vir a ser utilizada respeitando as limitações descritas nas normas acima citadas e as orientações dos órgãos ambientais. Destes 173 ha, 116 ha foram destinados à comunidade Renascer do MATR e o restante à comunidade Palmares do MTD.

Segundo este mesmo relatório, nesta ocasião, havia 170 famílias morando em barracos distribuídos em volta de toda a área. Com a restrição ambiental, em 2012 o INCRA deliberou a possibilidade de assentar apenas 25 famílias dos dois movimentos que permaneciam na área, o MATR e MTD, num modelo convencional de assentamento, de divisão da terra em lotes individuais, o que não atendia os anseios dos movimentos.

\footnotetext{
${ }^{4}$ Com base na Instrução Normativa SEMA/SEC/CAP/N. 2, de 22 de abril de 1988; a Lei Distrital n. 1.149, de 11 de julho de 1996; e Lei Complementar n $.46 / 2007$.
}

Com o auxílio dos membros do Movimento Rio São Bartolomeu, coordenado pelo Paulo César Araújo, o MATR apresentou ao INCRA um modelo de assentamento diferenciado. Este modelo foi baseado no modelo de Ecoagrovila, onde a propriedade da terra seria coletiva, as famílias não seriam titulares e haveria sessão de uso ao coletivo. A intenção era formar um assentamento que valorizasse a tradição de vida comunitária e coletiva e a identidade histórica construída durante os anos de luta pela terra, bem como uso sustentável dos recursos naturais e a convivência harmoniosa entre o homem e a natureza.

Com esta proposta, esperava-se que fosse possível aumentar o número de famílias a serem beneficiadas. Foram desenvolvidas várias reuniões do Movimento Rio São Bartolomeu Vivo com a comunidade Renascer com metodologias de "Design de Projetos colaborativos Dragon Dreaming" para o desenvolvimento do "sonho" de construir uma Ecoagrovila, mesmo não estando definido o número de famílias que seriam assentadas.

Assim, no final de 2013, o Movimento Rio São Bartolomeu Vivo procurou o Centro de Ação Social em Arquitetura Sustentável - CASAS da Faculdade de Arquitetura e Urbanismo da Universidade de Brasília - FAU UnB para desenvolver 0 projeto do parcelamento da Ecoagrovila Renascer. Ao longo de 2014, o escritório modelo CASAS desenvolveu estudos para a comunidade sobre o parcelamento e até o presente momento aguarda a definição do MATR e do INCRA sobre as famílias que serão assentadas para dar continuidade ao projeto no PROEXT 2015 com estudos de tipologias habitacionais para o Programa Nacional de Habitação Rural - PNHR no âmbito do Programa Minha Casa Minha Vida - PMCMV.

Portanto, o objetivo deste artigo é apresentar o processo de planejamento baseado no conceito de Ecovila e princípios de sustentabilidade para - desenho do lugar, com introdução de metodologias participativas, que envolveu estudantes e assentados do Movimento de Apoio a Trabalhadora e ao Trabalhador MATR. 


\section{Procedimentos Metodológicos}

O escritório modelo CASAS, vinculado à Federação Nacional de Estudantes de Arquitetura - FENEA foi criado em 2002 e, atualmente, é reconhecido no âmbito da Universidade de Brasília como Programa de Extensão (CASAS e PATUA). Tem como objetivo inserir o estudante na profissão de arquiteto urbanista e aproximar a universidade das comunidades carentes que fazem parte da real história do Distrito Federal. O CASAS, composto por estudantes voluntários ou bolsistas vinculados aos editais do Decanato de Extensão (DEX/UnB), atua em comunidades por meio de associações, organizações não governamentais e entidades que não têm condições de ter acesso ao trabalho de arquitetos. Como metodologia de trabalho interna, o CASAS segue a proposta de organização horizontal, na qual todos os membros têm participação ativa e de maneira igualitária, juntamente com os professores orientadores.

Como o escritório é composto por poucos estudantes, então, foi criada a disciplina Prática de Escritório Modelo de Arquitetura e Urbanismo (PEMAU), vinculada à FAU/UnB. Nesta disciplina cada grupo de alunos, juntamente com um ou mais professores orientadores, desenvolve um projeto escolhido pelo edital. O PEMAU utiliza-se de metodologias para o processo participativo, relativas à abordagem do projeto arquitetônico enquanto ferramenta de aproximação com as comunidades, das quais a equipe de estudantes e professores, juntamente com a comunidade, desenvolvem a metodologia adequada a cada projeto. É de grande importância esta parceria a fim de verificar as reais necessidades e desejos daquela comunidade, bem como o saber local e materiais disponíveis no local. Ao mesmo tempo espera-se capacitar as pessoas daquela comunidade para que elas próprias possam construir o projeto, utilizando para isso princípios mais sustentáveis.

Para coordenar a disciplina o CASAS convida dois professores da FAU, de forma que estes, em conjunto com os alunos, criarão metodologias de abordagem e construção do projeto arquitetônico com um viés social. Esses professores são responsáveis por estabelecer qual o produto a ser entregue ao final do semestre, segundo os objetivos da demanda. No primeiro semestre de 2014 o tema do PEMAU foi a Ecoagrovila Renascer.

O método de processo de projeto foi dividido em cinco fases: (1) pesquisa teórica realizada pelos estudantes e professores de PEMAU/CASAS sobre o Programa Nacional de Reforma Agrária, Programa Casulo e modelos de parcelamentos do solo, como vilas, vilarejos, ecovilas, agrovilas e permacultura; (2) reuniões e visitas ao assentamento para conhecimento dos anseios da comunidade Renascer e análise do contexto; (3) estabelecimento de parâmetros de projeto para o desenho de ecovilas baseados em princípios de sustentabilidade, morfologia e uma linguagem de padrões; (4) metodologia participativa para o processo de projeto " $\mathrm{Da}$ Realidade ao Sonho" com quatro propostas alternativas, utilizando a dinâmica interativa do Café Mundial ${ }^{5}$ que tem a capacidade de trabalhar a diversidade e complexidade no grupo, fazendo emergir a inteligência coletiva; (5) apresentação final das propostas à comunidade.

\subsection{Fase 1: Pesquisa Teórica realizada pelos estudantes e professores do PEMAU/CASAS}

A comunidade Renascer luta pela posse da terra desde 2004, e hoje, enfrenta o processo de parcelamento do terreno e assentamento das famílias que serão selecionadas. Portanto, encontra-se, no momento, na fase mais difícil do processo, das 170 que vivem no lugar (ou apenas demarcam o lote com barraco), somente 40 famílias do MATR e 20 do MTD serão assentadas. A pesquisa surge como uma necessidade de entender como os órgãos estão envolvidos no processo, os trâmites a enfrentar

\footnotetext{
${ }^{5}$ Café Mundial é uma prática que permite incluir a comunidade no processo de projeto através de sua participação ativa em dinâmicas de exposição e debate - segue-se uma descrição mais detalhada no item 2.4 Fase 4.
} 
até à organização espacial das áreas individuais e coletivas, construção das casas, bem como os princípios a seguir para responder ao modelo de assentamento que vem sendo idealizado pela comunidade.

\subsubsection{Pesquisa sobre políticas públicas voltadas para assentamentos rurais}

O INCRA tem como missão a gestão da reforma agrária do país mantendo um cadastro nacional das áreas rurais e administrando as terras em posse da União. Atua com o intuito de implantar modelos compatíveis com cada região e que promovam a proteção ambiental bem como o desenvolvimento sustentável dos assentamentos. Suas principais preocupações são a regularização fundiária, a reforma agrária participativa, o trabalho social e a qualidade da moradia. Por sua vez, a reforma agrária pretende atender aos princípios da justiça social, desenvolvimento rural sustentável e o aumento da produção. Segundo a Norma de Execução INCRA nำ4/2005, os beneficiários são os agricultores sem terra, aqueles cuja posse não ultrapassa um módulo rural do município e o posseiro assalariado, parceiro ou arrendatário. É de responsabilidade do mesmo órgão a aprovação do parcelamento e as diretrizes para o seu desenho, assim como a assistência técnica à comunidade e a implantação da infraestrutura básica no assentamento: acessos, saneamento básico e rede elétrica (responsabilidade do Município quando se trata da modalidade Casulo). O INCRA define quantas famílias vão ser assentadas baseando-se em critérios como o tamanho da família, a sua força de trabalho, idade, tempo de atividade agrícola, renda anual da família e a moradia no município, e também observando a capacidade de suporte da área através de suas características físicas e geoeconômicas (segundo o "Relatório de Viabilidade Ambiental do Imóvel"). E ainda, considera o movimento social e seus critérios de seleção, como o tempo de acampamento que gera frequentemente conflitos uma vez que é comum algumas famílias estarem cadastradas mas não morarem efetivamente no local - a demora leva algumas famílias a procurar trabalho e residência nas cidades próximas para subsistir, deixando apenas os barracos ocupando a área, como foi possível identificar no Renascer.

O Plano de Desenvolvimento do Assentamento - PDA é um dos documentos mais importantes no processo, pois comprova a viabilidade do projeto junto à assistência técnica de um órgão governamental, como a Empresa de Assistência Técnica e Extensão Rural - EMATER. Nele ficam caracterizados tanto o território como a comunidade, os recursos disponíveis e aqueles que urgem acesso, bem como o projeto da proposta de organização espacial $e$ as dinâmicas futuras de produção agrícola (e outros modos de subsistência como práticas artesanais, por exemplo), com os apoios necessários e serviços sociais básicos.

Quanto à organização espacial, a pesquisa permitiu reconhecer uma homogeneidade nas soluções encontradas, e que se apoia em Nogueira (2007) que considera existirem poucos modelos que tendem a ser continuamente replicados: o tipo "quadrado burro", o tipo agrovila, o tipo raio de sol e unidade familiar e terras comuns. Ver na tabela 1.

Tabela 1: Tipos de organização espacial nos assentamentos da reforma agrária, segundo Nogueira (2007).

Tipo de Assentamento Esquema
Quadrado Burro: Divisão do
terreno em parcelas
semelhantes ou iguais,
distribuídas ao longo das
vias como num tabuleiro
xadrez, com lotes
individuais. Cada lote




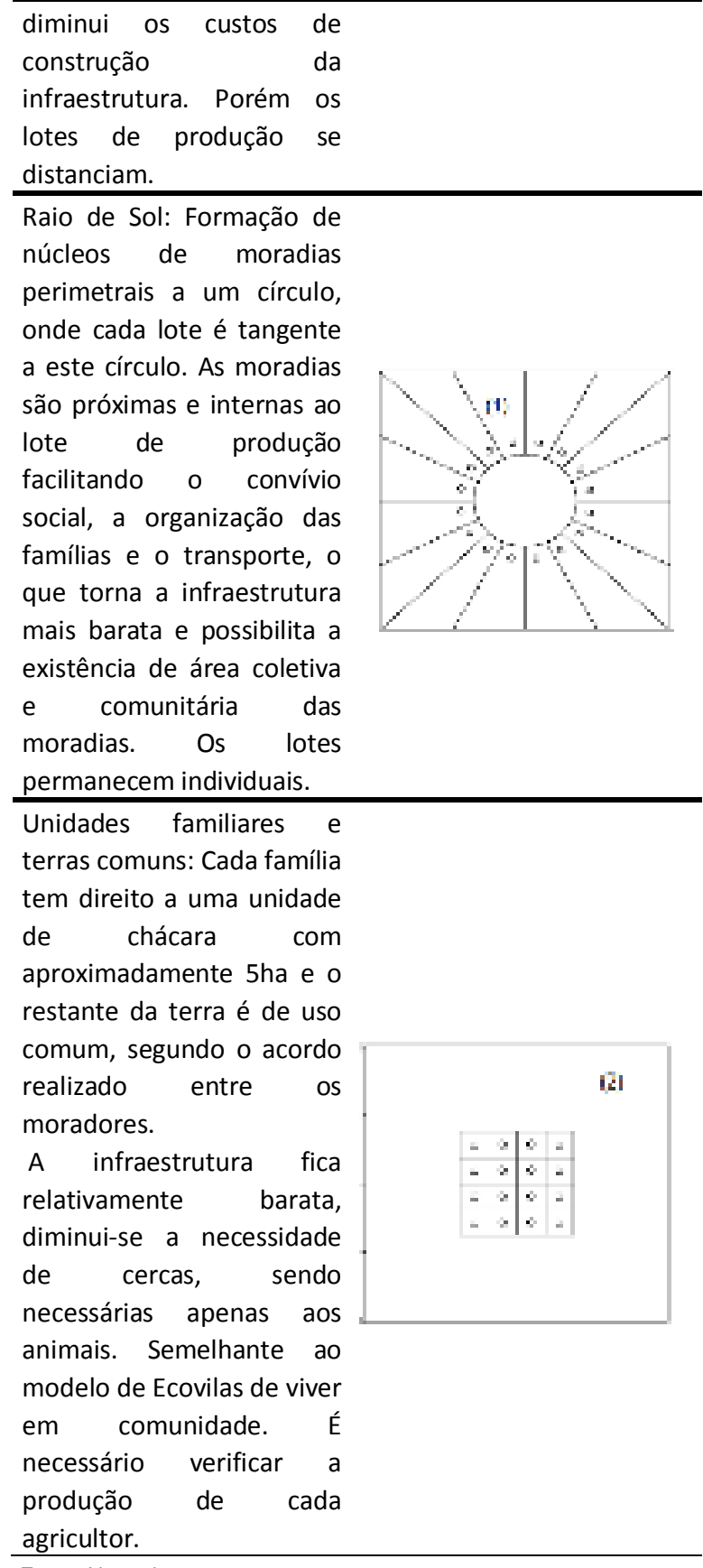

Fonte: Nogueira, 2007

Dentre eles reconhece-se maior e menor grau de coletivização da terra, de existência de espaços comunitários, de distância entre as moradias (parâmetros que segundo Holanda (2013) seriam responsáveis por atribuir qualidade - Urbanidade - aos espaços), bem como de impactos ambientais na questão do caminho das águas, de compactação do solo, e de melhor aproveitamento da produção de alimentos. A comunidade Renascer, em seu projeto de assentamento, seguirá o modelo Casulo, proposta do INCRA que deverá influir no tipo de organização espacial escolhida. É um modelo se destina primordialmente às áreas rurais com proximidade aos centros urbanos, como é o caso da comunidade Renascer, a $24 \mathrm{~km}$ de Brasília. Promove a descentralização e visa minimizar o êxodo rural através da geração de empregos para o campo e do aumento da produção familiar e comunitária de alimentos. Destina-se a assentamentos com pelo menos 15 famílias em lotes individuais, cada lote com fração mínima de parcelamento ou de até 4 módulos fiscais, em que suas atividades promovam a agroecologia, a sustentabilidade social, econômica e ecológica. A prefeitura municipal por sua vez é responsável por garantir a infraestrutura básica necessária para a implantação do assentamento além de resguardar o domínio da área destinada ao projeto.

\subsubsection{Pesquisa sobre vilas, vilarejos e agrovilas}

O processo de planejamento do assentamento leva a construção de expectativas de moradia e cotidianos pela comunidade, e partindo dessa vontade comunitária se desenvolvem também os planos e perspectivas que provam a viabilidade do projeto. No caso do Renascer, a agroecologia e o senso de comunidade são dois pilares estabelecidos desde o primeiro contato, tendo sido apresentado como "sonho" ${ }^{\text {a }}$ construção de um modelo de ecoagrovila. Para isso foram pesquisados conceitos como vilarejo, vila, agrovila e ecovila.

Desde sempre as vilas e vilarejos são exemplos de vivência comunitária e resiliência no meio rural (e mesmo urbano), com grande expressão por toda a Europa, mas com casos interessantes em todo o mundo. A aproximação das habitações e a relação destas com o território de produção agrícola gera um sistema de trocas e relações de interdependência entre os membros integrantes que ressignifica a noção de assentamento - bem distinta do modelo individualista e disperso de lotes de 2

\footnotetext{
6 Metodologia participativa "Dragon Dreaming" utilizada pelo Movimento Rio São Bartolomeu Vivo antes do Escritorio Modelo iniciar o processo de planejamento.
} 
ha ou mais com moradia de apenas uma família. A propriedade privada tende a reduzir sua importância perante $\mathrm{o}$ bem comum e a economia baseia-se num sistema de trocas e práticas solidárias. Estas áreas rurais apresentam uma clara alternativa ao sistema capitalista que enfrenta uma crise profunda em cidades por todo o mundo. Em Portugal, por exemplo, sente-se um retorno a essas práticas e modos de vida, sendo repovoados vilarejos e vilas abandonadas pelo êxodo rural das décadas anteriores. Práticas como o ecoturismo, turismo rural, produção orgânica de alimentos, entre outras, são práticas cada vez mais comuns na luta contra a crise econômica e o desemprego. Já no Brasil, um modelo com bastante potencial para dinamizar o rural é o modelo de agrovila, geralmente engrenado pela existência de cooperativas e fundada nos princípios da agricultura familiar e a produção de renda no campo. Tendem a localizar-se em áreas com recursos naturais disponíveis e relativamente próximas à cidade. Distinguem-se três tipos de modelos de agrovila: as de sobrevivência (em que a força de trabalho da família trabalha fora); as de subsistência (que conseguem absorver a força de trabalho da família); e as empresariais (que contratam mão de obra de fora). Das várias estudadas, destaca-se a "Agrovila Cidade do Bem" (Mauriti, Ceará) localizada numa área vetada ao abandono e cuja população sofria com a extrema pobreza, e que hoje é local de produção intensa de caju e gera renda e emprego para a sua população.

\subsubsection{Pesquisa sobre assentamentos humanos mais sustentáveis - Ecovilas e Permacultura}

Ecovila representa um modelo ideal para a aplicação dos princípios de sustentabilidade aos assentamentos humanos. Surge como forma de agregar ao assentamento dinâmicas sociais, funcionais e agrícolas que sigam as práticas da ecologia profunda (Andrade, 2005) buscando uma nova significação para sua vivência e trabalho comunitário, mais frequentemente no meio rural. Fundeia-se na necessidade de um novo modelo de moradia e comunidade, em resposta a esta realidade mundial de exaustão dos recursos. Gilman (1992) define ecovilas como "assentamentos de proporções humanas, funcionalmente completas, onde as atividades do ser humano se integram inofensivamente ao mundo natural, de forma a ajudar o desenvolvimento saudável deste e poder perdurar por um futuro indefinido". Assim, tratase de um modo de viver e produzir ecologicamente responsável e em que perpetua o senso de comunidade e partilha. Adota uma postura holística, em que cada indivíduo é parte integrante de um todo orgânico e age de acordo com as regras e ensinamentos da natureza (Andrade, 2005) - o indivíduo, ou a comunidade em si, assume-se parte do ecossistema e não superior a este.

Seus princípios orientadores, segundo Braun (apud Andrade, 2005) são a ecologia; a agricultura e alimentação orgânica; as tecnologias alternativas (mecanismos criados a partir da utilização e reutilização consciente dos recursos disponíveis - biotecnologia, bioconstrução, etc.); a arquitetura ecológica (maior cuidado com a escolha dos materiais, frequentemente naturais, locais ou reciclados, e relação intrínseca com o ambiente natural em volta); o dinheiro alternativo (adoção de métodos de troca alternativos ao sistema bancário tradicional, prática de uma socioeconomia solidária); a permacultura; a integração social (estimulando a vivência em comunidade, interação com a comunidade externa e a dinâmica de tomada de decisão de forma coletiva); a espiritualidade (práticas que estimulam $o$ crescimento do ser e o autoconhecimento, sempre vinculados a uma estreita relação com a natureza); e por fim o desenvolvimento sustentável (interligado a todos os anteriores e visando a prudência ecológica, igualdade social e o desenvolvimento da socioeconomia). Com isto, a ecovila desenvolve inúmeras práticas e modos de vida que propiciam um estado de fusão com a natureza, uma postura mais saudável perante o gasto de recursos e muitas vezes, torna-se espaço promotor da cura do ecossistema.

No caso do DF, com o desafio eminente de salvar o cerrado da extinção, a postura da 
comunidade Renascer, ao desejar organizar-se segundo este modelo (agregado ao da agrovila), oferece um potencial de preservação e regeneração para o território e seus recursos, associando aos princípios da permacultura e aos agroflorestais. Para além da produção agroecológica e do senso forte de comunidade, o sistema de assentamento em modo de ecovila permitiria fugir aos modelos individualistas de parcelamento da terra e à especulação imobiliária que os acompanha, em particular no DF. Um uso coerente e consciente dos recursos permitiria, também, atenuar as dificuldades atuais com o acesso a água, uma vez que os métodos permaculturais garantem uma menor necessidade do recurso em comparação com os métodos agrícolas tradicionais de monoculturas.

\subsection{Fase 2: Reuniões e visitas ao assentamento para conhecimento dos anseios da comunidade Renascer e o seu contexto}

Ao longo do semestre foram realizadas 3 visitas ao assentamento, sendo que na quarta visita, o CASAS convidou alguns moradores da Comunidade Renascer para conhecer o Instituto de Permacultura - IPOEMA. Na primeira visita os moradores receberam os estudantes do CASAS com o almoço para celebrar as "boas vindas". Na segunda visita, os estudantes da disciplina de PEMAU/CASAS fizeram uma análise do local, percorrendo quase todo 0 assentamento e, no final houve uma grande roda de conversa para "ouvir" os anseios da comunidade. Ali foi reforçado o sonho de um projeto de Ecoagrovila.

$\mathrm{Na}$ terceira visita, já com os padrões selecionados e riscos preliminares, os estudantes e professores organizaram um "Café Mundial" para troca de saberes que será relatado na fase 4.

\subsection{Fase 3: Estabelecimento de parâmetros de projeto para 0 desenho de ecovilas baseados em princípios de sustentabilidade, morfologia e uma linguagem de padrões \\ Conforme foi descrito na introdução, devido à}

proximidade com a área urbana, e aos quesitos do Programa Casulo, procurou-se como fundamentação teórica/metodológica, autores e métodos que tratam do urbanismo agrário, participativo, ecológico e da morfologia espacial. Em primeiro lugar, foram levantados os elementos de desenho urbano e as expectativas sociais quanto ao desempenho da forma urbana baseada no método Dimensões Morfológicas do Processo de Urbanização - DIMPU - (Holanda, 2013 e Kolhsdorf, 2006) que contempla os aspectos bioclimáticos, econômicos, funcionais, sociológicos, topoceptivos e expressivosimbólicos. Em seguida, buscou-se autores que trabalham com princípios ecológicos para 0 desenho de assentamentos urbanos e/ou rurais, como a permacultura (Andrade, 2005; Mollison, 1998, Sattler, 2007; Andrade, 2014) e a gestão ecológica da água. Os padrões (parâmetros de projeto) relacionados aos princípios de sustentabilidade de uma maneira geral, ou atrelados às dimensões da sustentabilidade social, econômica e ambiental, funcionam como "códigos geradores" de soluções de projeto, que se tornam recursos valiosos de comunicação com a comunidade.

O conceito de padrão está relacionado à solução de uma questão recorrente na arquitetura, porém essa solução não apresenta uma fórmula única que obriga a arquitetura a seguir uma determinada expectativa estética ou estrutura pré-definida. Cada padrão pode gerar diversas soluções arquitetônicas de acordo com as condições locais.

\subsection{Fase 4: "Da Realidade ao sonho": metodologia participativa para 0 processo de projeto com dinâmica do "café mundial" e propostas de níveis de realidade diferentes}

Após a sistematização dos padrões para a proposição do desenho do parcelamento foram também estipulados diferentes níveis de realidade para a execução dos projetos para que a demanda técnica fosse cumprida e os "sonhos" referidos igualmente explorados. Devido à longa espera das famílias, parecia essencial começar com uma visão prática e uma abordagem direta do problema, sem 
questionar os requisitos obrigatórios já estipulados (levando em consideração a proposta existente, disponibilizada pelo corpo técnico do INCRA) - o que se refletiria no primeiro Nível de Realidade. Daí em diante, de acordo com as pesquisas, esses requisitos são questionados, bem como o modelo a aplicar, apresentando visões mais ampliadas para a sustentabilidade deste projeto de assentamento.

Ainda assim, em todas as propostas, os quesitos de parcelamento da terra foram mantidos pela urgência em seguir com a aprovação do projeto de assentamento. Apesar de uma legislação bem elaborada e conhecedora dos valores ecológicos necessários para revigorar o meio rural, como visto anteriormente, a experiência prática com o INCRA revela uma postura rígida quanto às formas de assentamento clássico e alguma resistência para com as intenções projetuais que tendem para o espaço comunitário - como a posse comunitária da terra, entre várias outras - pela parte das equipas técnicas, como se pode ver pela proposta desenvolvida pelo órgão, na Figura 4. Neste sentido, há o risco de todo o aprendizado teórico e potencial comunitário não serem aproveitados por uma clara rejeição à inovação.

Figura 4: Parcelamento proposto pelo INCRA.

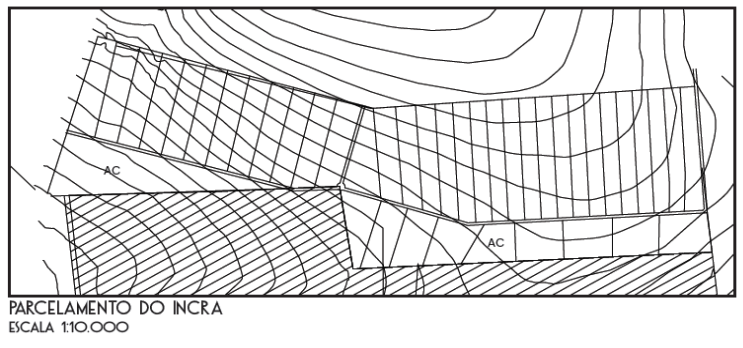

Fonte: Google Earth
Figura 5 e 6: Fotografias do assentamento.
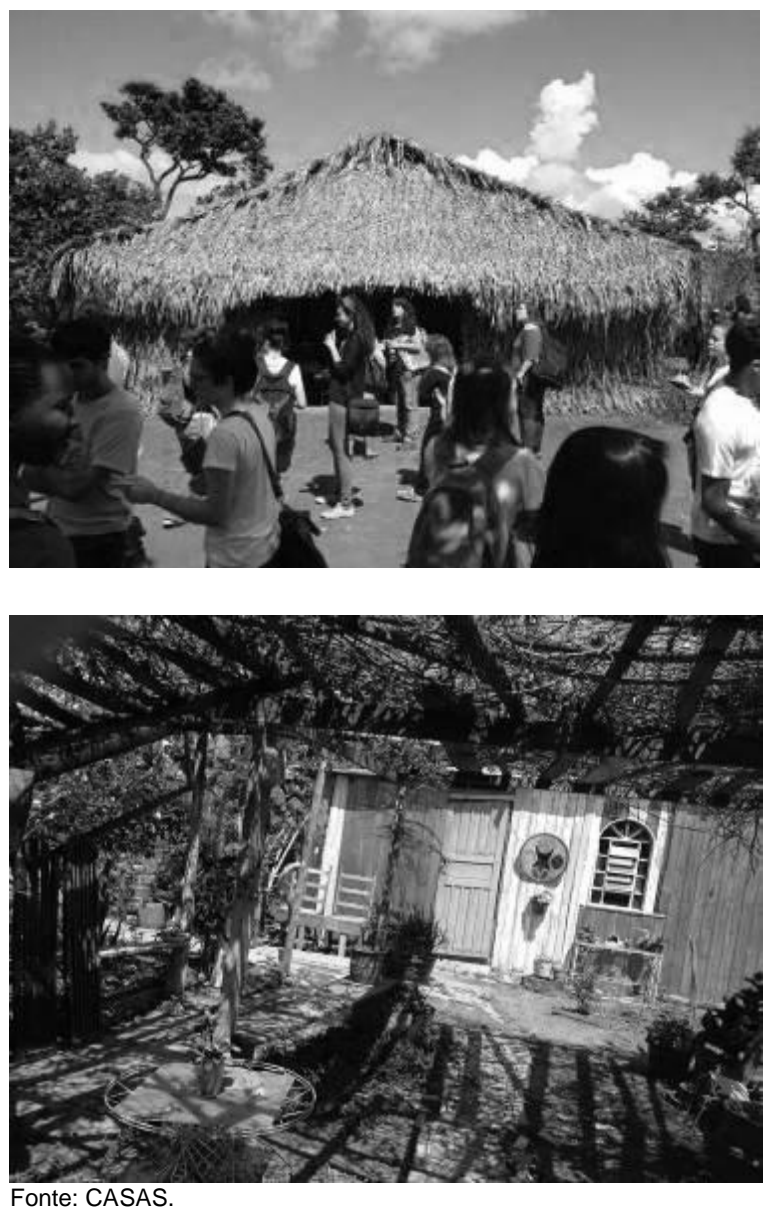

\subsubsection{Café Mundial e o desenvolvimento das propostas finais}

Partimos dos níveis de realidade para o desenvolvimento do primeiro esboço das propostas, e a partir desse momento, com a participação da comunidade para dar seguimento ao tipo de projeto ambicionado um projeto com a comunidade e não apenas para ela. Pela dificuldade de deslocamento dos moradores até à universidade e devido à necessidade de cumprir a grade do semestre, buscou-se um método intensivo de participação da comunidade no projeto. O Café Mundial baseia-se num processo participativo simples para trabalhar a complexidade e diversidade no grupo, promove a emergência da inteligência coletiva $^{7}$. O diálogo é pensado em grupos e, neste caso, levou apenas algumas horas. Os

7 Informação recolhida de http://cocriar.com.br/biblioteca/metodologias/worldcafe/, consultado em 06.03.2015. 
moradores foram divididos em 4 grupos para que as equipes pudessem circular entre todos com suas propostas e recolher seus testemunhos (figuras 7 e 8).

As percepções e aprendizados coletivos recolhidos permitem coletar informações preciosas para o desenvolvimento dos projetos. Esta experiência permitiu o crescimento das propostas e um mais claro entendimento dos desejos dos moradores. Suas opiniões distintas e seus raciocínios sobre os esquemas de organização ali propostos foram reveladoras para as equipes como ilustrados nas Figuras 7 e 8 .

Cada grupo ouviu os moradores e todas as propostas se aproximaram das necessidades expostas. Ficou clara a vontade pela posse individual da área do lote e o desagrado geral perante a diminuição da área privada em prol da coletiva. Emergiu a consciência de um conflito aceso a respeito de quais e quantas famílias permaneceriam no local, de que a universidade não havia tido conhecimento antes. Entendeuse que os ideais comunitários não eram consensuais e que a nossa proposta a respeito do "sonho" era apoiado apenas por uma parte do grupo presente. Muitas outras contribuições foram dadas pelos moradores, considerando-se suas práticas agrícolas e métodos de trabalho bem como suas expectativas quanto à posição da habitação no lote e no assentamento, e suas necessidades de aproximação com os vizinhos. Acima de tudo, reforçou-se a permanência dos lotes com as dimensões estipuladas pelo INCRA e todas as propostas se repensaram de modo a permitir, informalmente, um comportamento coletivo apesar disso. Foram incorporadas às propostas as demandas de funções comunitárias muito específicas, como a casa da farinha ou a venda de artesanato, bem como as estratégias que os grupos referiram a respeito da produção de renda, além da agricultura - turismo ecológico, restauração, pousadas, etc.
Figura 7 e 8: Registro fotográfico do Café Mundial.
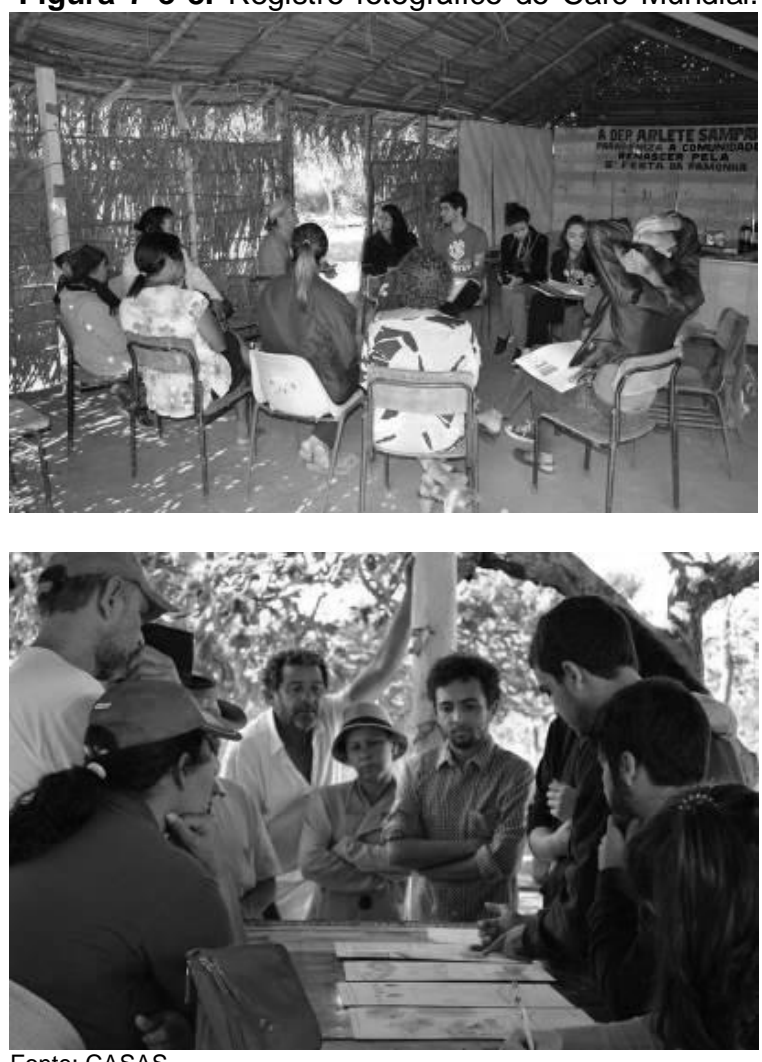

Fonte: CASAS

\section{Fase 5: Resultados das propostas "da realidade ao sonho" e a apresentação à comunidade}

Como resultado do processo, chegou-se a quatro propostas de estudo do parcelamento do solo, definidas no final do semestre.

Tabela 2: Proposta grupo 1

\begin{tabular}{|c|c|}
\hline & \\
\hline $\begin{array}{l}\text { 10 nível de realidade - } \\
\text { Procura realizar o mínimo } \\
\text { de alterações com } \\
\text { relação ao projeto } \\
\text { definido pelo INCRA. } \\
\text { Nessa instância são } \\
\text { pretendidos } 40 \text { lotes de } \\
2,5 \text { ha podendo ser } \\
\text { agrupados em conjuntos } \\
\text { de } 10 \text { lotes e onde os } \\
\text { estudantes trabalham a } \\
\text { questão do zoneamento } \\
\text { permacultural, } \\
\text { drenagem natural, áreas } \\
\text { de centralidade a partir } \\
\text { das vias existentes, além } \\
\text { de melhoramentos na } \\
\text { infraestrutura do lote. }\end{array}$ & $\begin{array}{l}5 \text { agrupamentos de } 10 \text { famílias } \\
\text { - 0,5ha do lote para moradia e } \\
\text { subsistência e 1,5ha para } \\
\text { plantação comunitária. Via } \\
\text { única para acesso aos } \\
\text { agrupamentos e às áreas } \\
\text { comunitárias; Vias internas a } \\
\text { cada agrupamento. } \\
\text { Agrupamentos com praças } \\
\text { comunitárias e sistema de } \\
\text { cultivo integrado. Espaços } \\
\text { coletivos: 1. Restaurante, feira, } \\
\text { centro de turismo, } \\
\text { administração e Parque } \\
\text { Ecológico; 2. Centro político; } \\
\text { Escola; Horta Experimental; } \\
\text { Lago de contenção para água } \\
\text { da chuva; 3. Igrejas; Casa de } \\
\text { farinha; Depósito de } \\
\text { maquinários; Praça; Área de }\end{array}$ \\
\hline
\end{tabular}




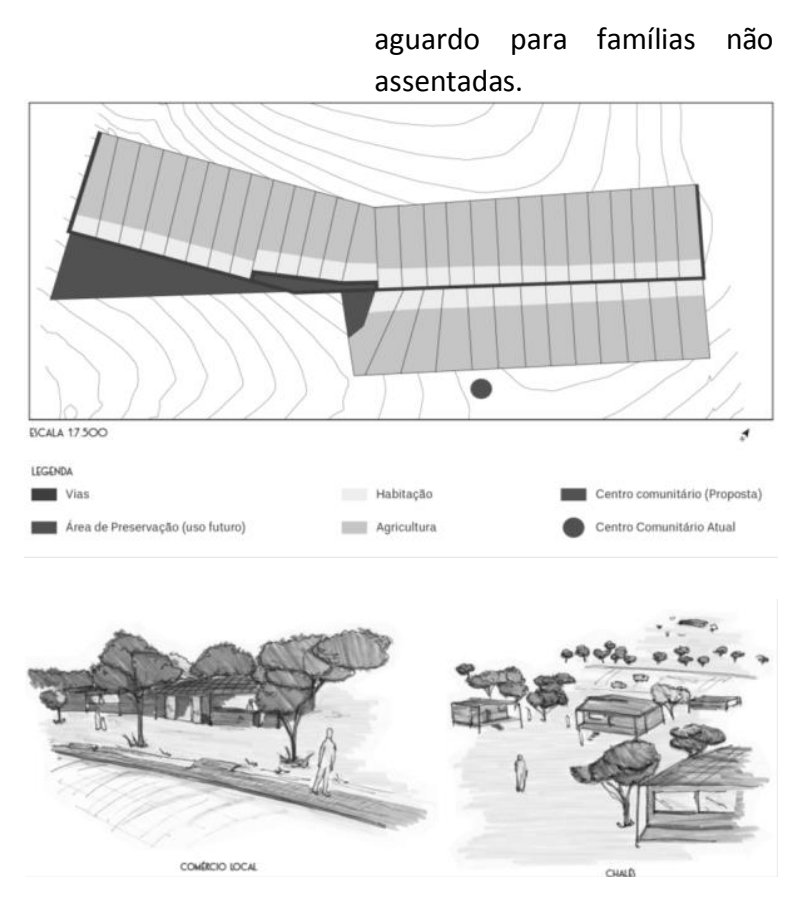

Fonte: Alunos Átila Resende; Bárbara Gomes; Felipe Hanna; Michelle Bastos; Paula Alves; Taís Alves

Tabela 3: Proposta grupo 2.

\begin{tabular}{|c|c|}
\hline & \\
\hline $\begin{array}{l}2 \text { o nível de realidade - } \\
\text { Este nível de realidade } \\
\text { permite algumas } \\
\text { alterações moderadas } \\
\text { com relação ao } \\
\text { planejamento inicial, } \\
\text { tanto na distribuição de } \\
\text { lotes quanto na } \\
\text { organização comunitária. } \\
\text { Também são trabalhados } \\
\text { 40 lotes com 2,5ha cada, } \\
\text { podendo estes ser } \\
\text { agrupados também em } \\
\text { conjuntos de } 10 \text { lotes. } \\
\text { São trabalhadas a } \\
\text { questões do zoneamento } \\
\text { permacultural, a } \\
\text { drenagem, os encontros } \\
\text { comunitários e demais } \\
\text { aspectos. }\end{array}$ & 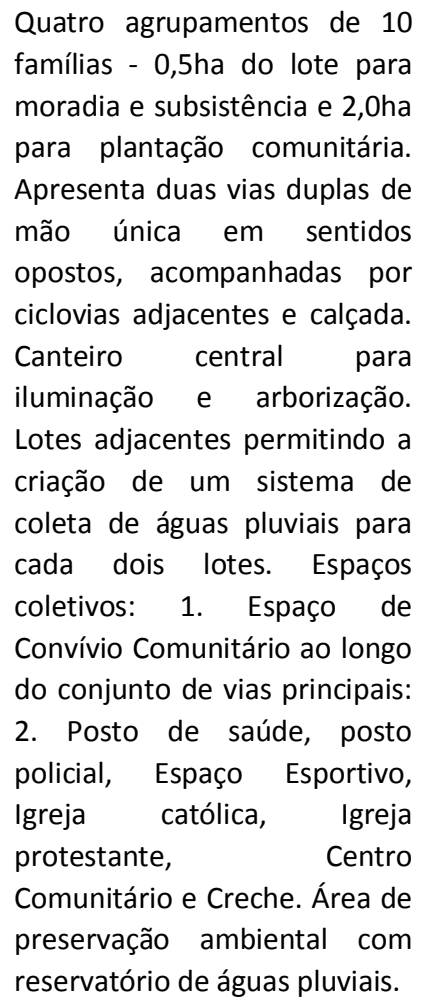 \\
\hline
\end{tabular}

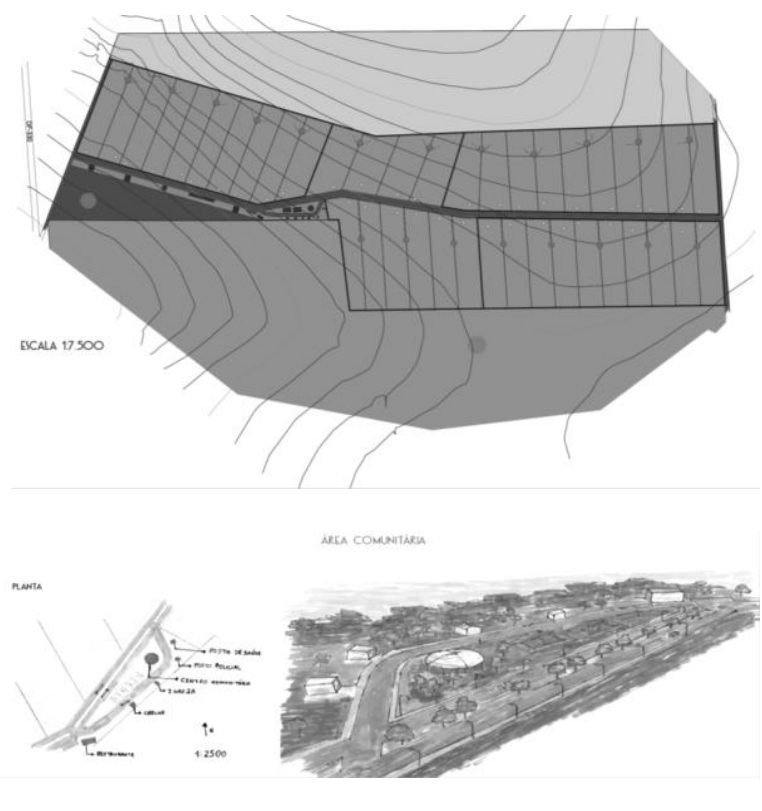

Fonte: Alunos Camila Garrido; Débora Quindere; Demarbique Sanca; Pedro Gomes; Raul Maravalhas; Roberta Carolina; Vanessa Figueiredo

Tabela 4: Proposta grupo 3.

\begin{tabular}{|c|c|}
\hline & \\
\hline $\begin{array}{l}\text { 3o nível de realidade - } \\
\text { Neste caso são } \\
\text { permitidas significativas } \\
\text { alterações do projeto } \\
\text { original, dando destaque } \\
\text { para a exploração do } \\
\text { conceito de urbanismo } \\
\text { agrário e de mudança } \\
\text { significativa de vias a } \\
\text { partir das curvas de } \\
\text { nível. São trabalhados } 50 \\
\text { lotes de 2,0ha cada onde } \\
\text { busca-se introduzir o } \\
\text { conceito de densidade } \\
\text { no parcelamento e } \\
\text { materiais bioconstrutivos } \\
\text { para a construção das } \\
\text { casas, além de outras } \\
\text { características } \\
\text { apresentadas nos outros } \\
\text { cursos. }\end{array}$ & $\begin{array}{l}\text { Quatro agrupamentos de } 10 \\
\text { famílias - lotes com } 2 \text { ha com } \\
\text { áreas de cultivo individual e } \\
\text { comunitário sem delimitação } \\
\text { estabelecida. } \\
\text { Uma via principal e trilhas de } \\
\text { passeio acompanhando a } \\
\text { reserva ambiental. Apresenta } \\
\text { via de deslocamento interno } \\
\text { interligando os agrupamentos. } \\
\text { Distribuição nuclear dos lotes } \\
\text { promovendo o contato entre } \\
\text { famílias, instalação de } \\
\text { infraestrutura e segurança } \\
\text { local. Prevê-se a criação de } \\
\text { praças locais em cada núcleo. } \\
\text { Espaços coletivos: } 1 . \text { Centro } \\
\text { comunitário (caráter turístico) } \\
\text { com: restaurante; vendas de } \\
\text { artesanato local; centro de } \\
\text { turismo e pousada; e } \\
\text { administração local. } 2 \text {. Parque } \\
\text { Ecológico com enfoque no } \\
\text { ecoturismo e na geração } \\
\text { alternativa de renda. }\end{array}$ \\
\hline
\end{tabular}



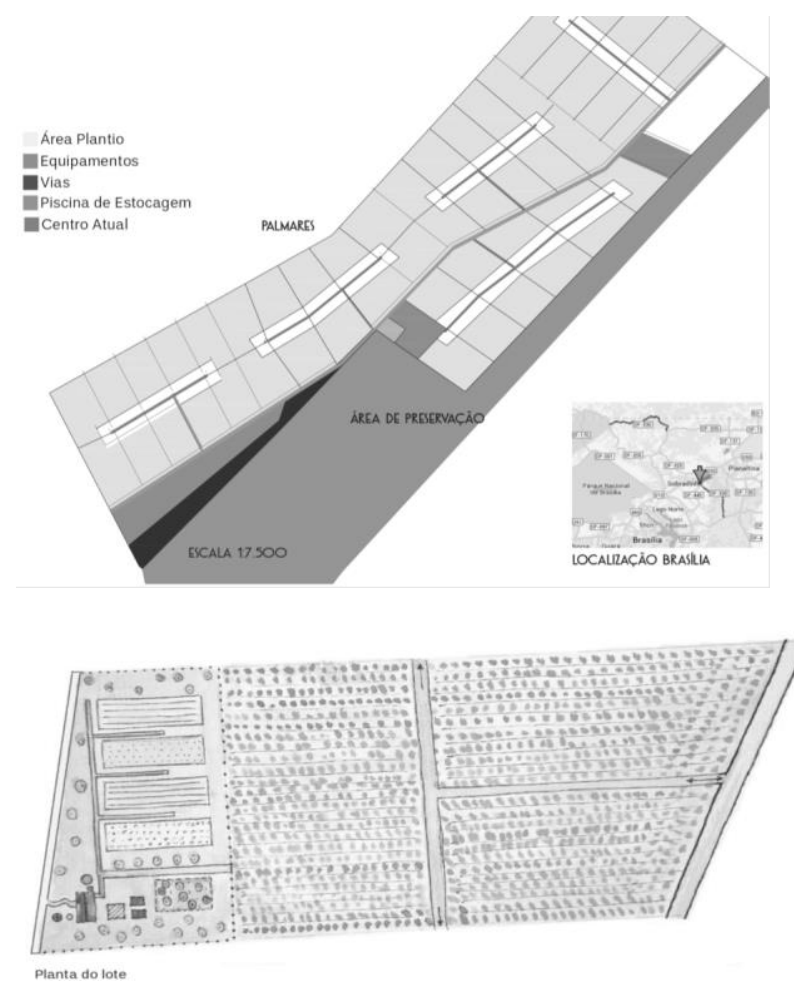

Fonte: Alunos André Dantas; Bruna Ruperto; Dalyana Lima; Gabriel Parente; Júlia Huff; Luísa Corrêa; Luiz Machado.

Tabela 5: Proposta grupo 4.

\begin{tabular}{ll}
\hline Descrição & Projeto \\
\hline & 4 agrupamentos de 10 famílias \\
& com distribuições distintas (lotes
\end{tabular}

40 nível de realidade - com 2ha) e núcleos em cada Este último permite agrupamento. Apresenta uma uma maior liberdade de via principal com trilha de zoneamento e passeio pela reserva ambiental e parcelamento dos lotes, outra conectando os núcleos ao além de possibilitar a centro comunitário. A alteração de vias e distribuição radial permite a áreas de preservação. aproximação das habitações Com essa realidade entre si e é pensada para que o busca-se atingir o sonho uso da área dos lotes possa ser da comunidade de usada para cultivo comunitário construir uma também. Espaços coletivos: 1. ecoagrovila. Para esse Zona de Expansão - para projeto são pretendidas famílias futuras; 2. 50 famílias com 2,0ha Desenvolvimento Econômico cada. Pretende-se o com restaurante rural; casa de adensamento farinha; casa de artesanato; e populacional em comércio em geral; 3 . formato de vilarejo Desenvolvimento Social onde serão exploradas Centro comunitário com: residências que se refeitório; duas igrejas; salão utilizem da para palestras e reuniões; praça Permacultura.
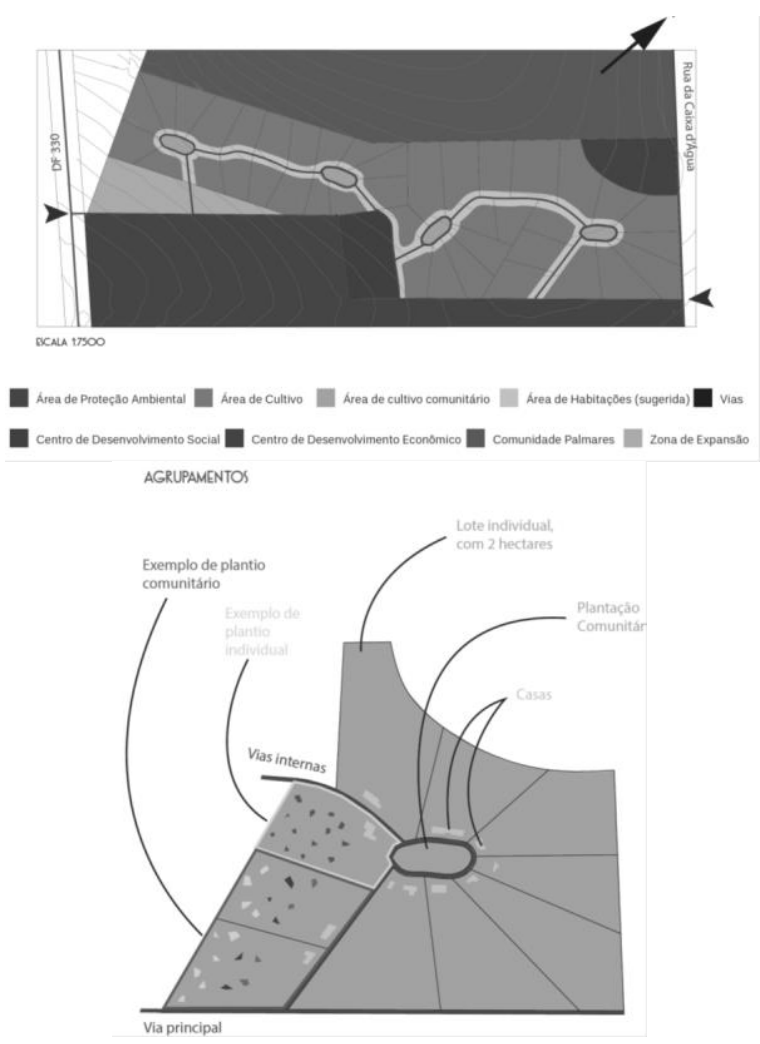

Fonte: Alunos Alyssa Volpini; Elisa Bermudez; Filipe Conde; Juliana Carvalho; Juliana Marchezan; Mayara Almeida; Vanessa Tourinho

As propostas foram apresentadas à comunidade e à universidade no final do semestre, num encontro organizado na Universidade de Brasília e aberto ao público, onde a comunidade teve acesso à concretização do projeto no qual participaram e que foi pensado para responder às suas expectativas.

Figuras 9, 10 e 11: Registro fotográfico da apresentação das propostas:

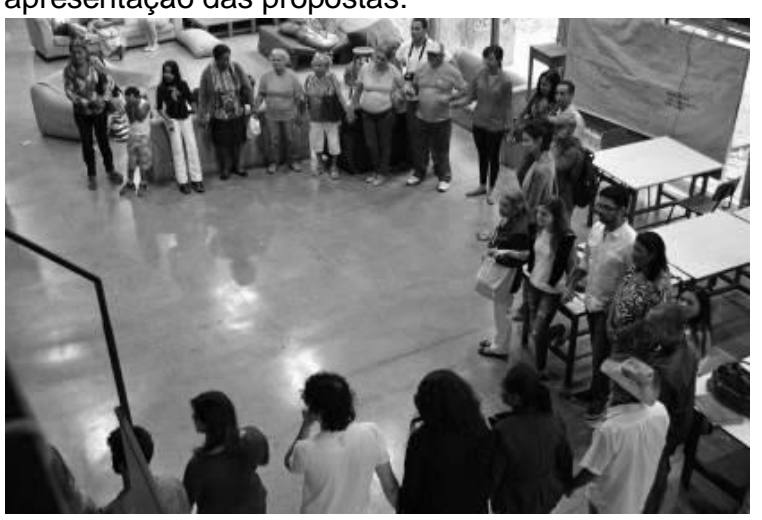



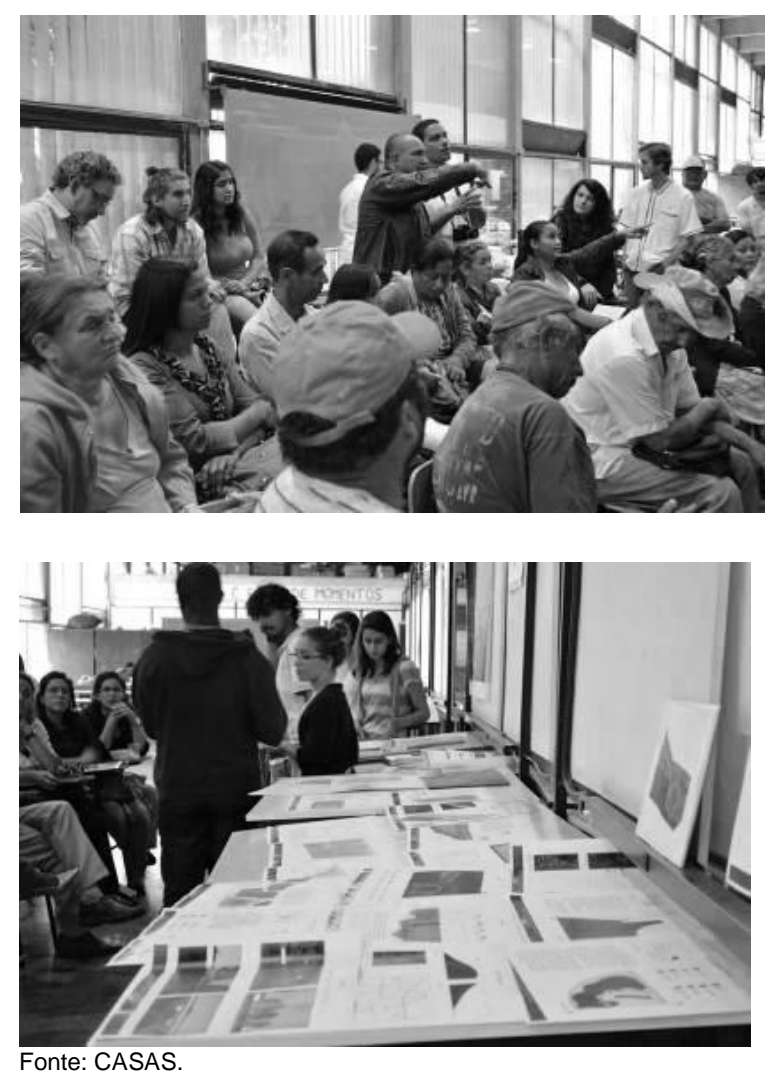

\section{Considerações Finais}

Todo o processo se mostrou muito rico em troca de experiências e aprendizado, mas fica a frustração de uma situação de conflito que não permite $o$ avanço das propostas de forma mais eficiente. $O$ fato de toda a comunidade participar das reuniões sem a definição de quais famílias irão permanecer no território, gera um desconforto que se revela incompatível com a prática do projeto participativo. Entende-se que a universidade tem uma grande contribuição a dar, ao repensar os modelos de assentamento, particularmente quando tem conhecimento da situação real. Enquanto urbanistas e projetistas, a mediação de projeto e conflito não pode ser um ato paralelo, daí a importância profunda do trabalho social coordenado com 0 trabalho técnico. Outro aspecto a ser ressaltado é que grande parte dos conflitos poderiam ser evitados se houvesse uma visão mais holística para tratar da relação cidade/campo no contexto da bacia hidrográfica, como a questão da densidade construtiva do gradiente do urbanismo agrário, visto que as familias que não permanecerão no local terão que ser realocadas em outra área, ocasionando muitas vezes maiores impactos ambientais na bacia.

\section{Referências}

ALEXANDER, Christopher; ISHIKAWA Sara; Murray, SILVERSTEIN; JACOBSON, Max; FIKSDAHL-KING, Ingrid; ANGEL, Shlomo. A Pattern Language. New York: Oxford University Press, 1977.

ALEXANDER, Christopher. Urbanismo y parcipación. Colección Punto y Línea. Barcelona: Editorial Gustavo Gilli, 1978.

ANDRADE, Liza Maria Souza de. Agenda verde $X$ Agenda marrom: inexistência de princípios ecológicos para o desenho de assentamentos urbanos. Dissertação (Mestrado) PPGFAU/UnB. Brasília, 2005.

ANDRADE, Liza Maria Souza de. Conexões dos padrões espaciais dos ecossistemas urbanos. Tese de doutorado PPG-FAU/UnB. Brasília, 2014.

BRASIL, Relatório de Viabilidade Ambiental do Imóvel - RVA. Fazenda salvia gleba 127. Assentamentos rurais: Renascer e Palmares.

HOLANDA, Frederico Borges. Os 10 mandamentos da arquitetura. FRBH.Brasília, 2013.

KOHLSDORF, Maria Elaine. Diretrizes gerais para as disciplinas de projeto de arquitetura e urbanismo. Curso de Arquitetura e Urbanismo Colegiado das disciplinas de Projeto de Arquitetura E Urbanismo do Centro Universitário UNIEURO. Brasília, 2006.

MOEHLECKE, J. Uma contribuição para o desenvolvimento de assentamentos humanos mais sustentáveis: identificação de padrões urbanos relacionados aos princípios de sustentabilidade. Dissertação (Mestrado em Engenharia) - Programa de Pós-Graduação em Engenharia Civil, UFRGS, Porto Alegre, 2010.

MOLLISON, Bill; SLAY, R. M..Introdução à Permacultura. Tradução: André Luis Jaeger Soares. Brasília: MA/ SDR/ PNFC, 1998.

NOGUEIRA, Renata Fernandes. A organização sócio-espacial do assentamento Olga Benário. Monografia, Geografia, Universidade Federal de Viçosa, Viçosa, 2007. 
SATTLER, Miguel Aloysio. Habitações de baixo custo mais sustentáveis: a casa Alvorada e o Centro Experimental de tecnologias habitacionais sustentáveis. Porto Alegre: Coleção Habitare, ANTAC, 2007.

PEREIRA, Cloviomar Cararine e PEIXOTO, Marcus. A importância da participação nos métodos de planejamento do desenvolvimento de assentamentos rurais. Sem data e Sem referencia. Disponível em http://www.sober.org.br/palestra/12/110479.pdf. Acesso em 05 de março de 2015. 